\title{
Bioethics in Psychiatric Institutions of Kosovo: Case Study
}

\author{
Miftar Zenelaj \\ Center for Integration and Rehabilitation of Chronic Psychiatric Patients-Shtime, Kosovo
}

Copyright $(\mathrm{C} 2017$ by authors, all rights reserved. Authors agree that this article remains permanently open access under the terms of the Creative Commons Attribution License 4.0 International License

\begin{abstract}
The Mental Health Department in Kosovo makes one of the more important departments of public health. Therefore, based on this specific importance, the contemporary reforms which have been undertaken in this department, have a special importance. This study is precisely focused on this department and its objective is to prove the level of observance of ethical principles during the treatment of psychiatry patents in hospital environments. The research objective ceases at the analysis of norms and ethical principles' obedience, as well as observance of legitimate rights of people with mental disorders. The study treats problems in an integral way and it analyses important ethical issues due to coming to a tangible conclusion. In order to provide answers to the research's questions, the research method is based on the use of anonymous questionnaires given to the medical staff and on patients' interviews. Bioethics as a new discipline interferes with many aspects of applying medical-psychiatric practices by posing various dilemmas, such as: Where and what does a psychiatrist practice ;How and why does a psychiatrist practice various diagnostic methods; When and how is the treatment of the psychically ill practiced; How much does the psychiatrist respect the patients' rights; How much are the principles and ethical norms being respected in a mental health institution: The respect of patient's rights about information and self-determination related to the treatment; Preserving/keeping medial secrets; Treating patients with dignity; Morally-ethical behavior of the medical staff in mental health institutions ;Observance of the International Convention about the Rights of Psychiatric Patients; The role of the psychiatrist in the compulsory psychiatric evaluation. Starting from the concept of psychic illnesses which present an individual's problem of living with the illness in his/her environment (community), because of the labeling and him/her being stigmatized as insane (a fool) constitutes a morally-ethical dilemma of our modern society. Insanity exists in the mind and behavior of the individuals who suffer from psychic disorders or spiritual illnesses whose substratum exists in his/her personality. This substratum can be organically-pathological but in most of the cases clinical experiences have shown that it can also happen as a result of psycho-social processes (traumas), by not excluding the concept of the individual's genetic
\end{abstract}

construction. In the past the psychiatric patients have been deprived of their legal freedom even though they have had mental capacity of making decisions for their best interests and their well-being. As an answer to this and partly because of other justified reasons The Human Rights Act claims: "Everyone's right to life shall be protected by law" This means that in Mental Health institutions patients' rights of exercising autonomy and making free choices, including the right to refuse treatment, must be respected. Psychiatric patients need to get the care they need, including protection of their self-harming behavior and always by respecting ethical principles and norms.

Keywords Psychiatry, Bioethics, Patient, Dignity, Ethical Norms

\section{Introduction}

"All people with mental disorders have the right to get high-quality treatment and responsible healthcare. They have to be protected of any unhuman form of treatment and discrimination".

WHO2003

\section{The Aims of the Research}

Empirical studies related to different ethical issues have shown that it is necessary to do a clinical and ethical research. The aim of this paper is to help:

1) Tracing and evolution of ethical principles in mental health institutions and

2) Reviewing the data which is related to the plausible ethical questions

Empirical findings about respecting: legal rights, ethical principles, the right to be informed, the right for decision-making, respecting dignity, the psychiatrist-patient/client relation and many other issues which are related to the fields of mental health which need to be based on the basic philosophies of big codes, on declarations and other relevant domestic and international 
documents about dignified treatment of human subjects.

More specifically, the objectives of this study are:

1. Research of the medical staff's knowledge about the ethical principles.

2. Determination of observance of the psychiatric patients' rights.

3. Observance of ethical norms and principles in a psychiatric clinic.

4. Determination of the influence of internal hospital factors on the obedience or disobedience of the ethical code by the medical staff in a psychiatric clinic.

5. Evaluation of dominant factors in diagnosing and successful treatment in a psychiatric clinic.

6. Analysis of intra-hospital conditions while treating psychiatric patients.

\subsection{Research Methodology}

This scientific work has been carried out following the development of two hypotheses:

\subsection{Auxiliary hypotheses $\mathrm{H} 1$}

If ethical principles and norms are adhered to by health workers, the quality of health services will increase.

\subsection{Auxiliary hypotheses $\mathrm{H} 2$}

If psychiatric patients are informed about their rights, the service will be improved and the satisfaction of patients will increase and will impact on the improvement of their mental health.

Based on the topic: "Bioethics in Psychiatric Health Institutions of Kosovo", it was concluded that the research has been conducted through the conception and definition of a transversal case study implemented with the health workers and patients of the Psychiatric Clinic of the University Clinical Center of Kosovo.

A case study is an empirical review which investigates a contemporary phenomenon within a context and in real time; the boundaries between the phenomenon under review and the context are not clearly defined and various sources of evidence are used. Initially, the Psychiatric Clinic of the Clinical Center of Kosovo has been identified as the subject of study, considering the fact that it represents the most objective, factual and efficient possibility of drawing the needed information to assume whether ethical and bio-ethical principles are being respected adhered to in Mental Health Institutions of Kosovo, and provide clear recommendations on what actions need to be taken and how to constantly improve medical services and bio-ethical treatment of patients within the code of ethics.

Materials and research methods: In order to obtain the desired answers on research questions regarding the hypotheses under review, the quantitative analysis has been used which was conducted through a standardized questionnaire. The process that has been followed during the implementation of the research is as follows:

Defining the population and selection of the sample: Based on the case study, it is considered appropriate to divide the target population of the research into two categories:

a) psychiatric patients and b) the medical staff working in the Psychiatric Clinic of the University Clinical Center of Kosovo. From these two population categories measures were taken to have the representative sample as inclusive as possible. Therefore, in the case of medical staff as well, it is was considered reasonable to include in the survey all the workers in the Psychiatric Clinic, given that their number is manageable for inclusion in the survey. As for the patients, a random selection has been made of those patients who are covered by the psychiatric clinic, with an intention of having the maximal objective demographic criteria without pre-defined elements. It is important to note that the only selection criterion for the patients was their mental capacity to respond.

\section{Research Results of the Psychiatric Patients' Questionnaire}

The permeate statistics is being used in order to analyze the results of the questionnaires about the observance of ethical norms and principles during hospital treatments of psychiatric patients.

In modern western society women have a higher percentage of mental illnesses than men. This difference can be attributed to the role of married women. Actually, it is shown that married women have a higher degree of mental disorders that married men.

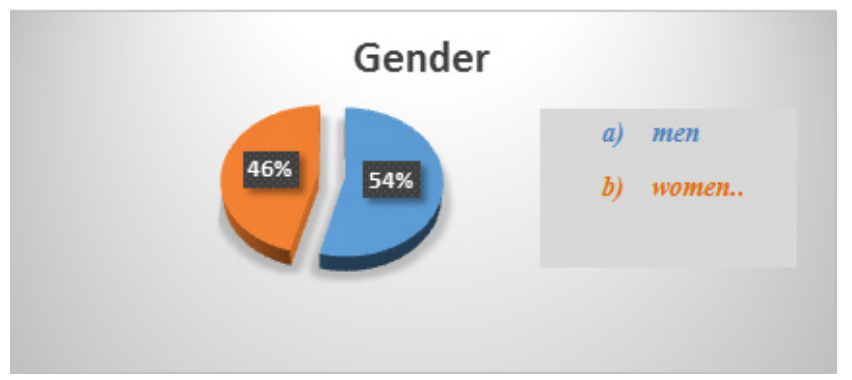

Chart 1.1. Gender

The results of the study in our psychiatric institutions have shown that women have a lower rate of mental disorders. In academic studies the prevalence of psychic disorders according to gender is almost equal.

In the Psychiatric clinic of University Clinical Service of Kosovo (UCSK), like in other clinics, repeated hospitalizations are dominant.

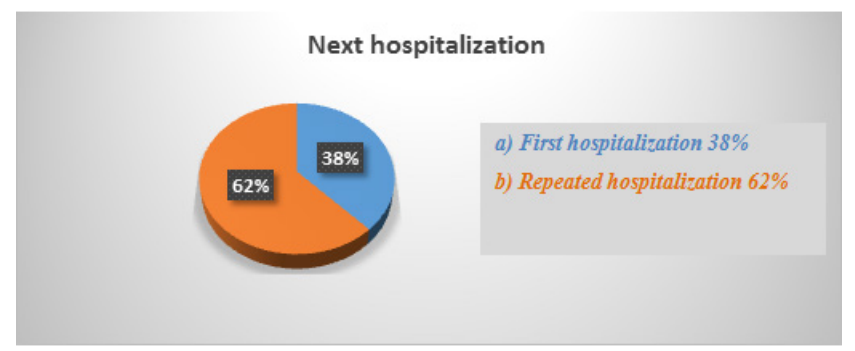

Chart 1.2. Repeated hospitalizations are prevailing 
As in many European countries, also in our country the observance of the right for making decisions about the treatment and hospitalization is regulated by the law. The obedience of the right for voluntary treatment as well as for the compulsory treatment is not at the level where it should actually be.

The prevailing form of hospitalization is the one where patients are being forced by their families.

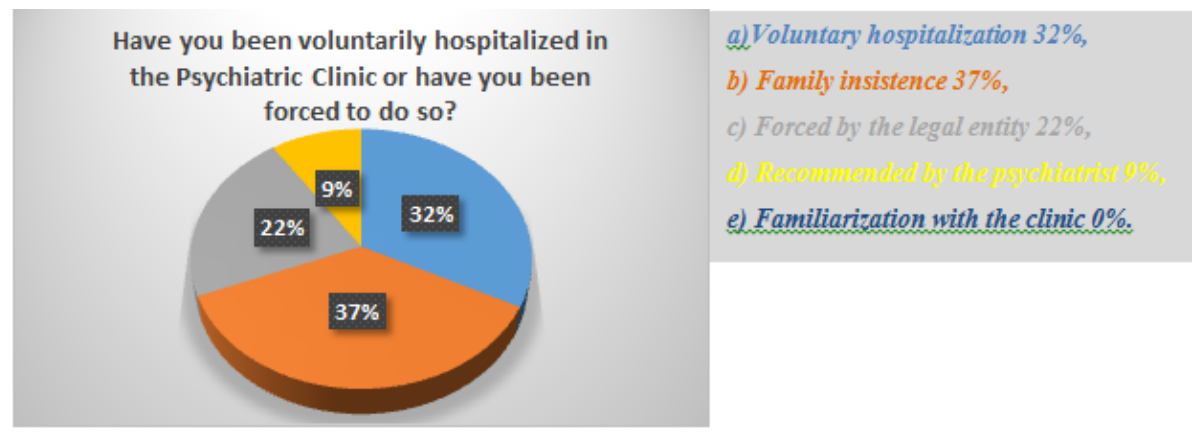

Chart 1.3. The results of the question "Have you been hospitalized in the Psychiatric Clinic voluntarily or have you been forced to do so?"

The right to get informed about to the illness, the patient's state, the illness prognosis, the chance of getting more advanced treatment, undesired effects of the treatment, risks and failures during the treatment- is the patients' elemental right. Needed information facilitates the patient to decide about the treatment for his illness in an independent way.

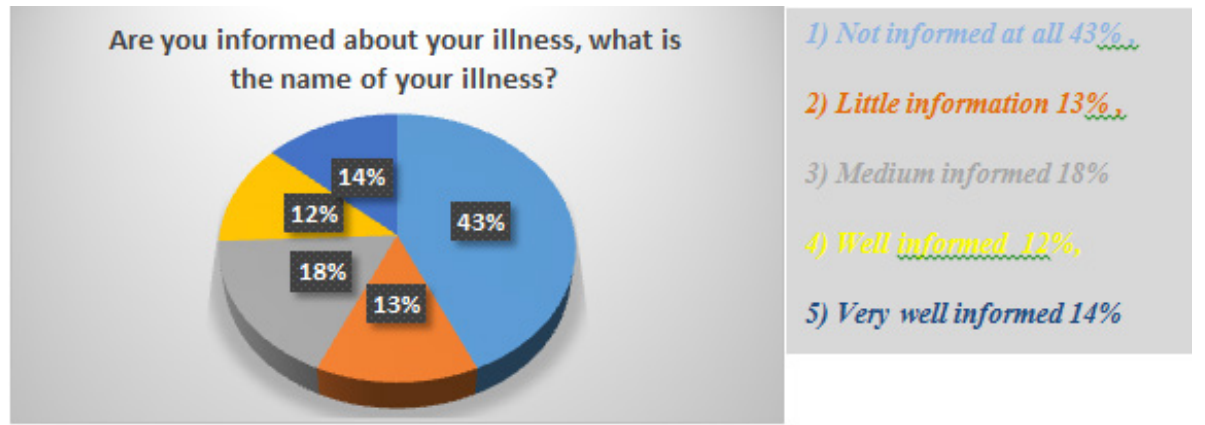

Chart 1.4. How much are the psychiatric patients informed about their illness.

You can see that the results show that very few have information about their illness or the name of their illness.

The United Nations Convention on the Rights of Persons with Disabilities is an authoritative legal document related to the rights of people with disabilities, because it also includes the rights of people with mental illnesses ${ }^{1}$.

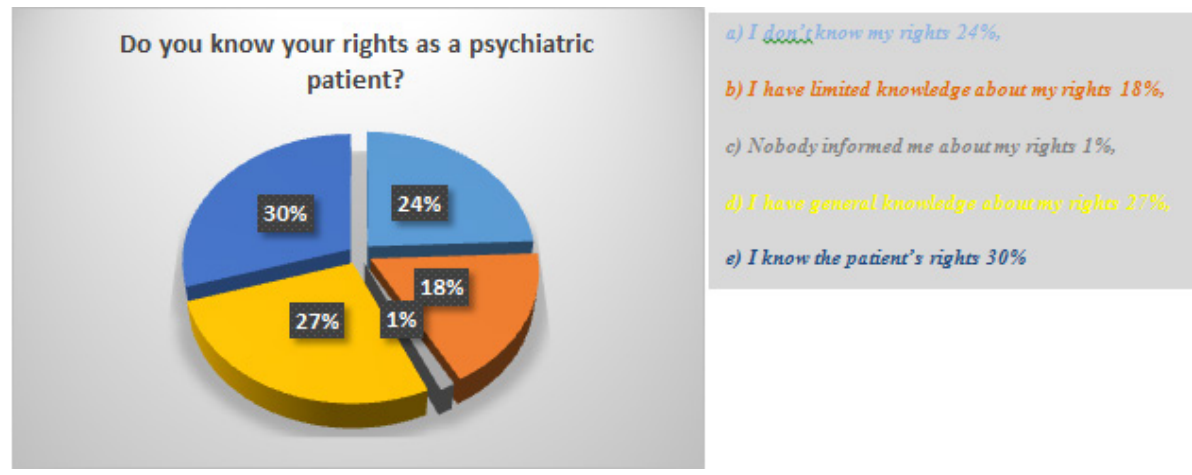

Chart 1.5. patient's rights

We have a diversity of answers when it comes to knowing their (patient's) rights, as you can see on the chart. The right about "getting informed and self-determination" of the patient in connection with the medical treatment means that he/she has the right to make decisions without pressure about receiving or refusing what is being offered by health care. Patient's choices and decisions made this way are free and willful. 


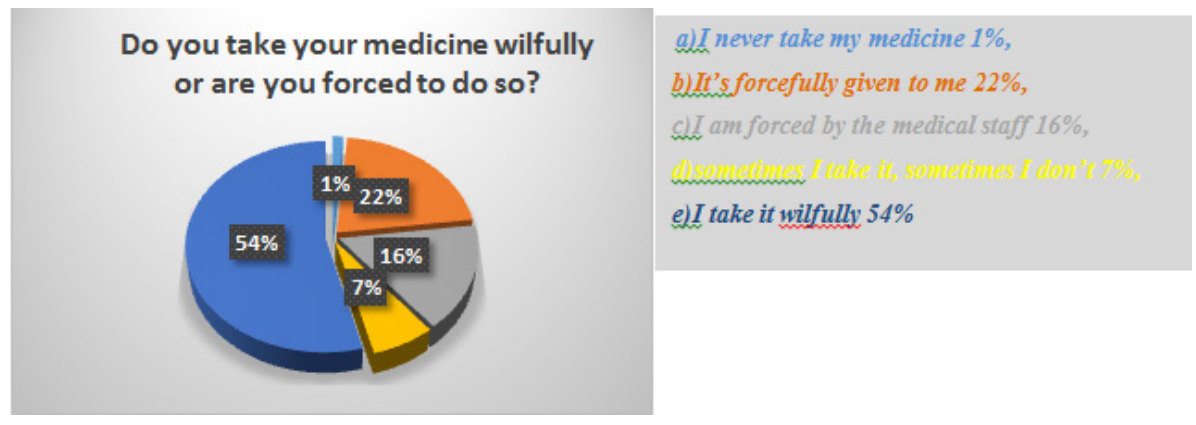

Chart 1.6. Do you take your medicine willfully or are you forced to do so?

It's shown that taking the medications has good rates because more than a half of the patients have given positive answers.

Generally, the psychiatrist and the medical staff have to understand and respect the psychiatric patient as a human being with special needs for treatment. Since the moment of the request for professional psychiatric help, the patients must be respected and you need to win the patient's trust and cooperation.

It's clear to see that the patients are satisfied with the respect shown by the medical staff, because $78 \%$ of the interviewed patients gave positive answers.

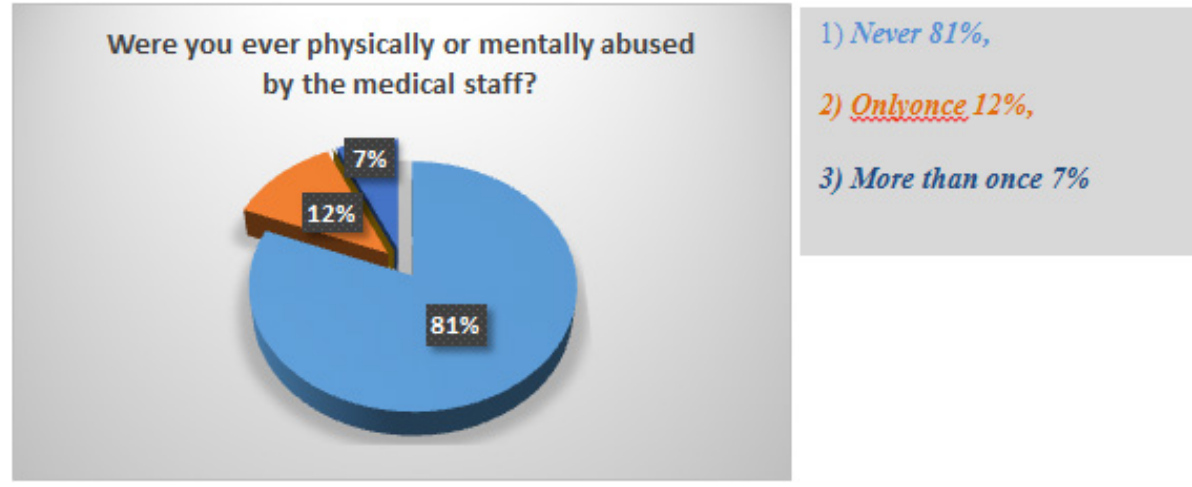

Chart 1.7. Were you ever physically or mentally abused by the medical staff.

Medical violations happen during medical practices caused by human carelessness while exercising their professional duty. Professional mistakes and disrespecting of the physical and psychical dignity are not rare, but these tend to be hidden from the staff. While the damaged patients or their families don't complain they make it impossible for the medical staff to escape from their ethical and legal duties.

It's confirmed that there is some physical abuse and there is still room for improvement.

In general medical practice doctors often come across sexual abuse and psychiatric disorders. The most frequent are patients with anxiety disorders, bipolar disorder, depression, Obsessive-compulsive disorder, PTSD, schizophrenia, sleeping disorders, somatoform disorders.

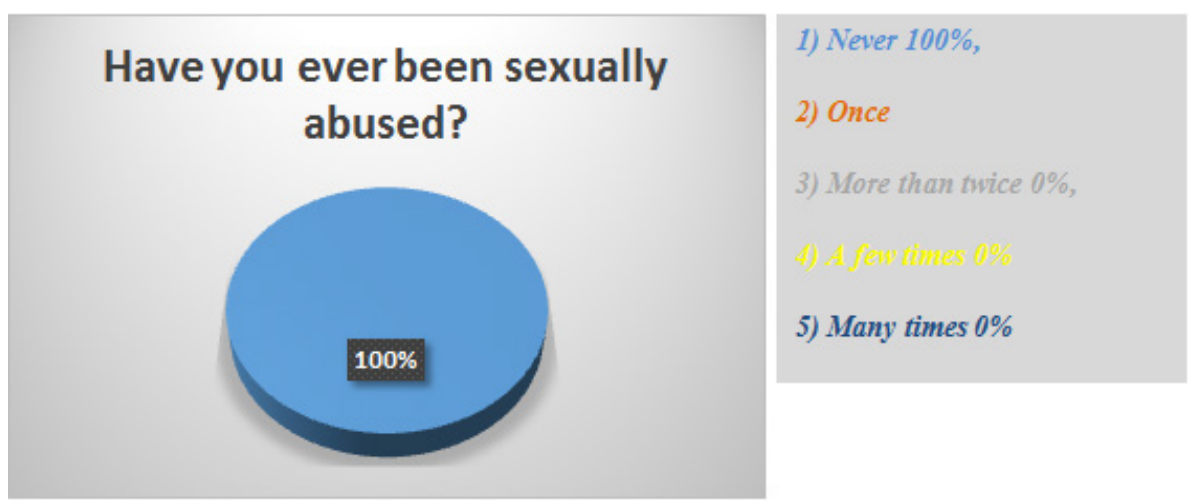

Chart 1.8. The results show that there were no sexual abuses. 
The medical staff actualizes cooperation with a group of people. This helps during the period of treatment of the patients where the need for communication and cooperation in family is essential.

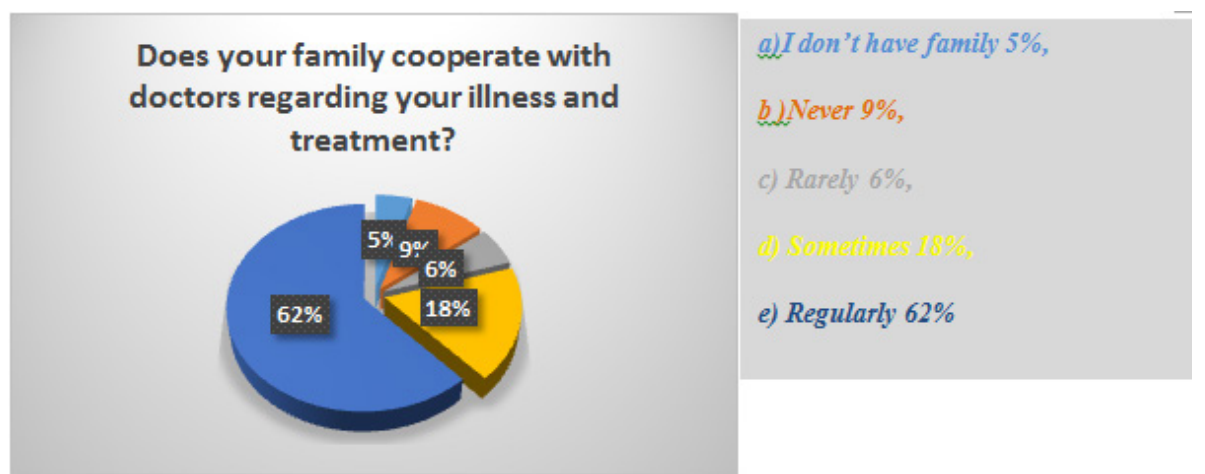

Chart 1.9. Does your family cooperate with doctors regarding your illness and treatment?

We got these results regarding the question: "Does your family cooperate with doctors regarding your illness and treatment?": You can see that the cooperation between doctors and family members is satisfying.

The period of staying in a psychiatric hospital depends on various factors. One of the main factors is the program and the protocol of the treatment which depends on the evaluation and the objective state of the patient and hispsychic status. It's usual that the treatments last for a specific period of time and the majority of people have to stay during this period.

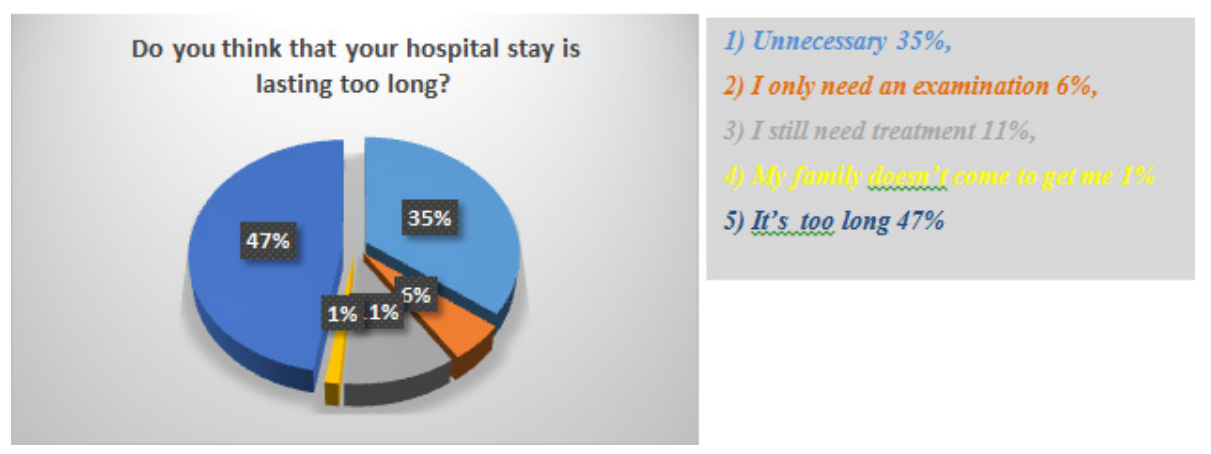

Chart 1.10. Do you think that your hospitalization is lasting too long?

The majority of the patients think that they're being held longer that they need to stay in the institution.

The development of rehabilitation and early modern psychiatric re-socialization with the help of professional- vocational therapy have shown successful results which have improved the clinic's status, functioning status and life quality. The acceptance of rehabilitation and integration, as a specific discipline was slow because of the conflicts between traditional and modern treatments.

As for re-socialization, rehabilitation and re-integration of patients after leaving the hospital, more attention should be paid.
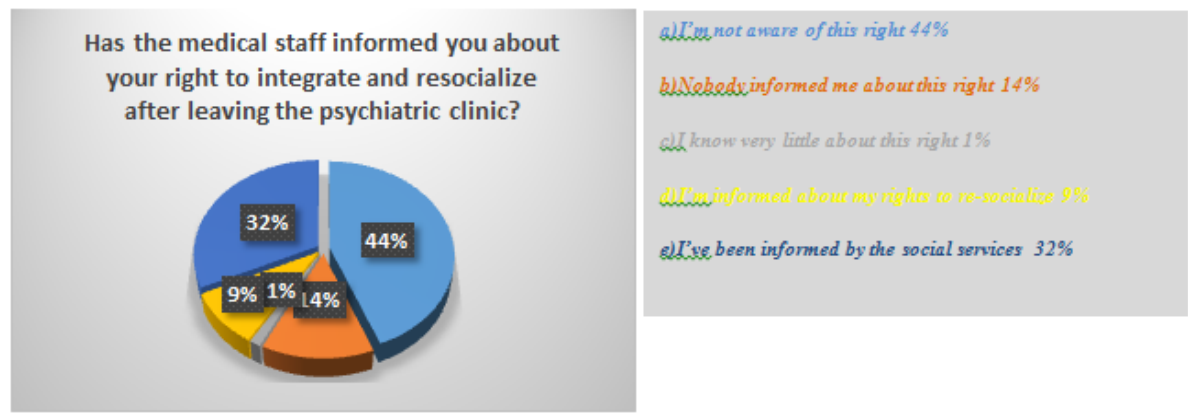

Chart 1.11. Has the medical staff informed you about your right to integrate and resocialize after leaving the psychiatric clinic? 


\section{The Results of the Medical Staff's Questionnaire Results in the Psychiatric Clinic}

The study sample consists of 92 people of the medical staff and registered psychiatric personel that holds a permanent posititon in the psychiatric clinic and belongs to the tertiary halth servile level- Clinical University Center- MUCK.

4.1. Mental Health's Medical Staff in the Psychiatric Clinics in our Country Consists of: Psychiatrists, Psychologists, Professional Licensed Nurses, Mental Health Technicians, Recreation Therapy Staff and Social Workers. This Structure is Foreseen for Multidisciplinary Treatment and Effective Needs of the Patients / Clinical Residents

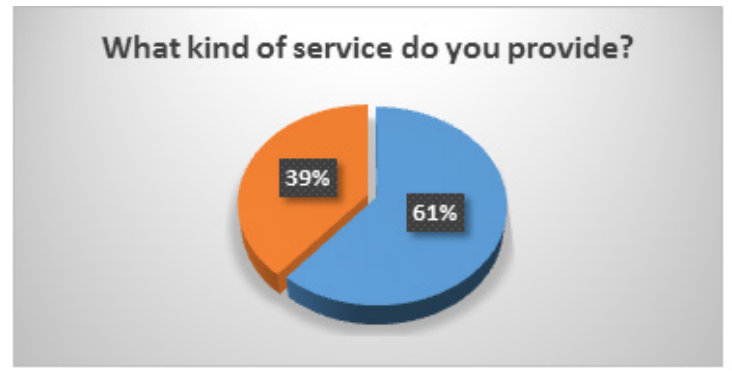
a) Nurse $61 \%$
b) Specialist $39 \%$

Chart 4.1. The number of nurses is dominant.

4.2. The Gender Ratio of the Medical Staff in the Majority of Psychiatric Clinics Shows that Males are Prevailing, whereas in Other Clinics Females Prevail. It is Thought that the Job Nature and the Challenges in Mental Health Clinics is the Reason of the Lower Concentration of Women

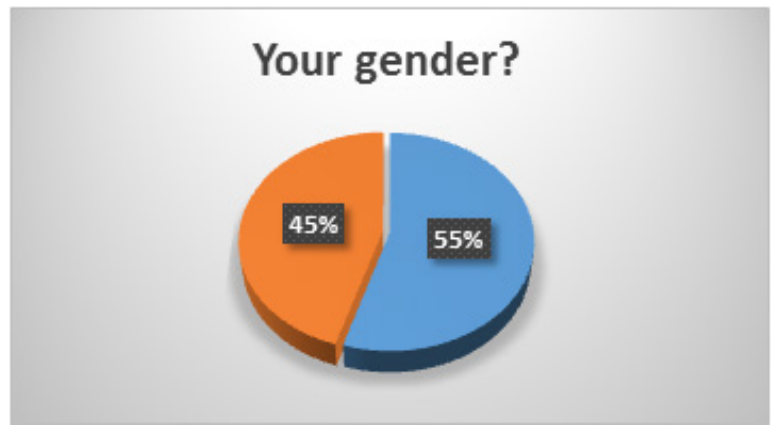
a) Male 55\%,
b) Female $45 \%$

Chart 4.2. Gender

4.3. The People that are Hospitalized and Treated Should be Given the Opportunity to Express their Points of View and these Points of View Should Be Taken in Consideration as Much as Possible. Special Attention Should Be Paid to Respecting Patients' Rights about Getting Treatment, Having their Privacy and Autonomy ${ }^{2}$

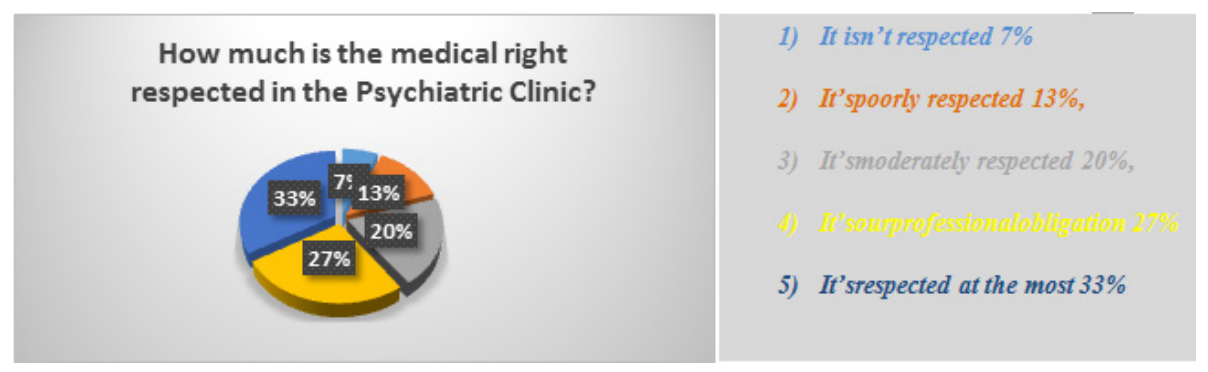

Chart 4.3. Even medical rights are generally respected, even though there's space for improvements. 
4.4. Moral Norms and Behavior Regulations Determine the Social Relations; they're Cohesive between Special Social Groups. Within these Norms and General Behavior Rules, Take Place those ones that Link the Relation between the Medical Staff and Patients in Mental Health Institutions ${ }^{3}$

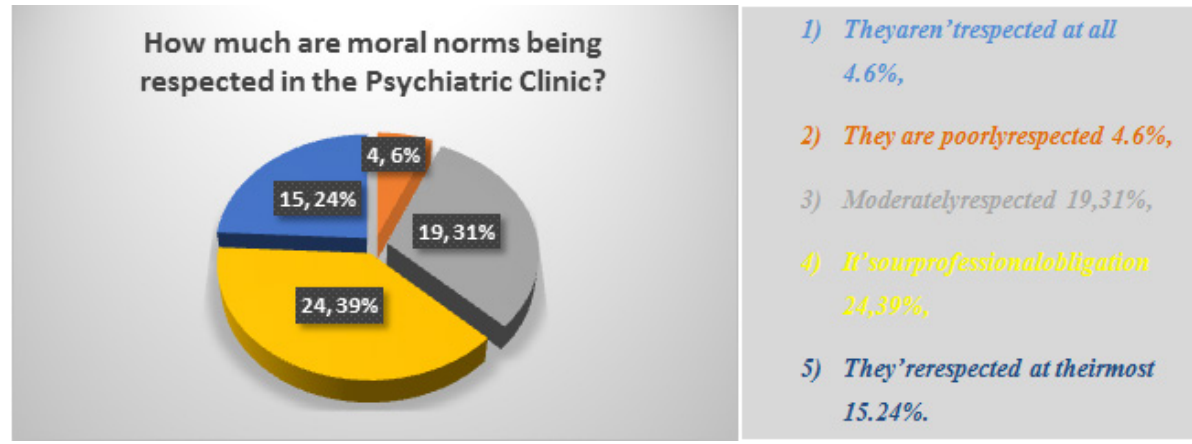

Chart 4.4. The majority of the medical staff think that the norms are being respected.

\section{5. "Always do What is Possible and in the Best Way Possible and for the Patient's Good, by Taking Care not to} Cause any Harm or Mischief." - Hippocrates 460 - 377 BC.

The Oath of Hippocrates was for the first time adapted and corrected by the Declaration of Geneva in 1948. The second time it was changed by the General Assembly of World Doctors (Venice Declaration, 1983). Whereas the latest modification was done in 1994, in Stockholm, by the General Assembly of World Doctors Association. This latest version is being used today all over the world ${ }^{4,5}$.

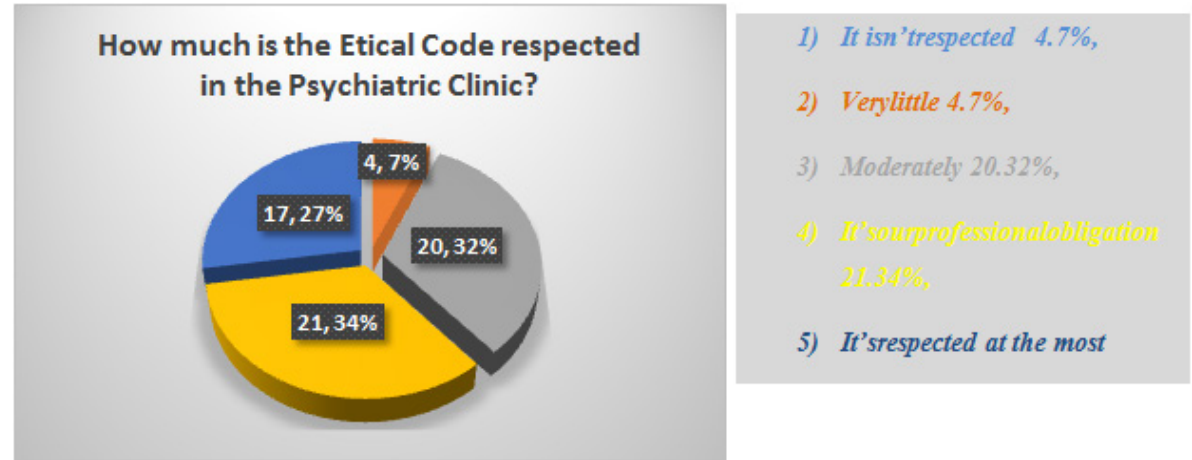

Chart 4.5. We can see that there is still room for improvement when it comes to respecting the ethical code and moral norms.

4.6. The right to be informed about their illness, their state, their illness prognosis, the possibilities of advanced treatment, undesirable side-effects, risks and about failures during the treatment is the basic right that is protected by the international convention of Geneva. Based on this a concept of "information and self-determination" of the patients has been developed.
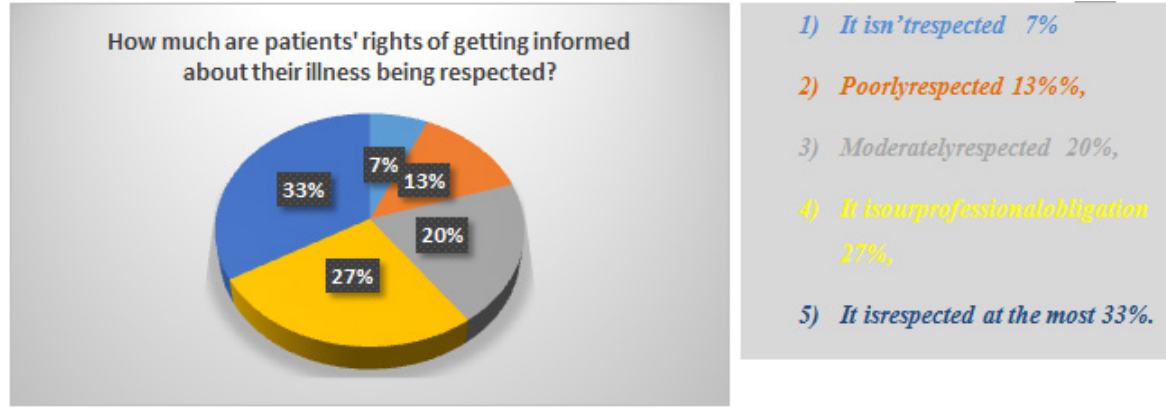

Chart 4.6. The patient's right to get informed is also incomplete and it is needed to work more in this field.

3Fulford, K. M, Moral Theory and Medical Practice. Cambridge, UK: Cambridge University Press, 1990.

4Drane, J. F. Clinical Bioethics: Theory and Practice in Medical Ethical Decision-making. Lanham, USA: Rowman \& Littlefield, 1994. 5Helmchen, H. \& Sartorius, N. Ethics in Psychiatry - European Contributions. Netherlands: Springer, 2010. 
4.7. Honouring Patients' Personality and their Autonomy is one of the Main Ethical Values and Medical Rights. The Patients' Autonomy is Protected by Legal Norms and it is Determined by Patients' Legal Rights. The Law has Reinforced Patients' Rights about Self-determination, but the Actual Practice isn't in Full Accordance with the Law

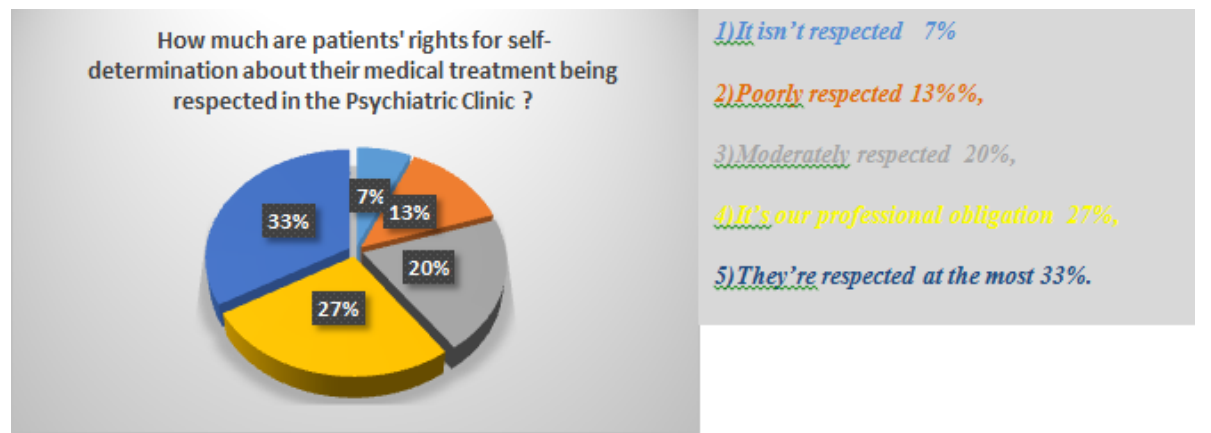

Chart 4.7. The results related to patients' self-determination in relation with treatment are similar to those about patients getting informed. Hence, the medical staff has to respect patients' rights about self-determination more ${ }^{6 .}$

\section{8. "She Hits me Everywhere on My Body, Because I Have Limited Abilities, She Blames Me for My Disability."-- "Psychiatric Patient N.N"}

Psychiatric patients were often a subject of psychic and physical abuse in psychiatric institutions. Every violation of psychic and physical dignity not only influences the victim, but also the society in general $^{7}$.

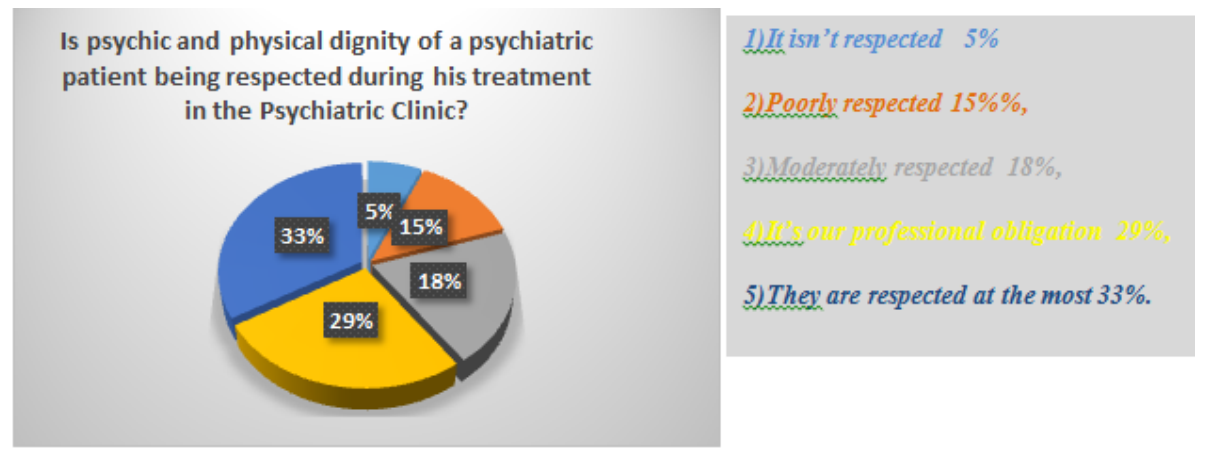

Chart 4.8. The results show that the respect for patients' psychic and physical dignity isn't at the appropriate level.

4.9. The Patients Have the Right to Expect that We Won't Reveal Personal Information Which We Were Entrusted with during Their Professional Treatment. Nowadays, a Medical Secret, in Many Countries All around the World, is Protected by Legal Norms and by Disrespecting Them Those Who Reveal Them Carry Moral and Legal Responsibility with Themselves

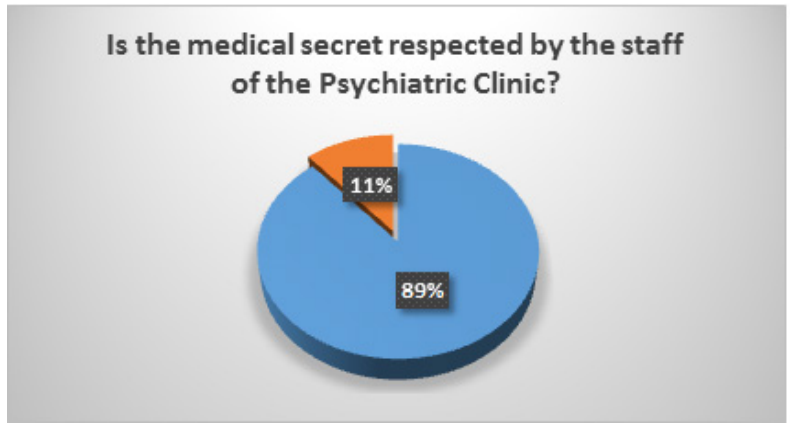
a) Yes, it isrespected $89 \%$
b) No, it' not respected11\%

Chart 4.9. It is shown that keeping the medical secret is at a satisfactory level.

6Doyal, L. \&Sheather, J.. Mental Health Legislation Should Respect Decision Making Capacity. BMJ: British Medical Journal, 331(7530), pp. 1467-1469, 2005.

7 Edwards, R. B. Ethics of Psychiatry: Insanity, Rational Autonomy, and Mental Health Care. Prometheus Books, New York, USA,1997. 
4.10. Criteria for Diagnosing Mental Disorders are Classified by ICD-10 and DSM-IV, V Manuals. They are Completely Scientific and Objective. The Diagnosis Mustn't Get Disfigured Because of Cultural, Economic, Social, Political etc. Reasons. Psychiatric Patients Shouldn't Be Misused for Others' Interests and in this Aspect Ethical and Professional Norms Should Be Protected.
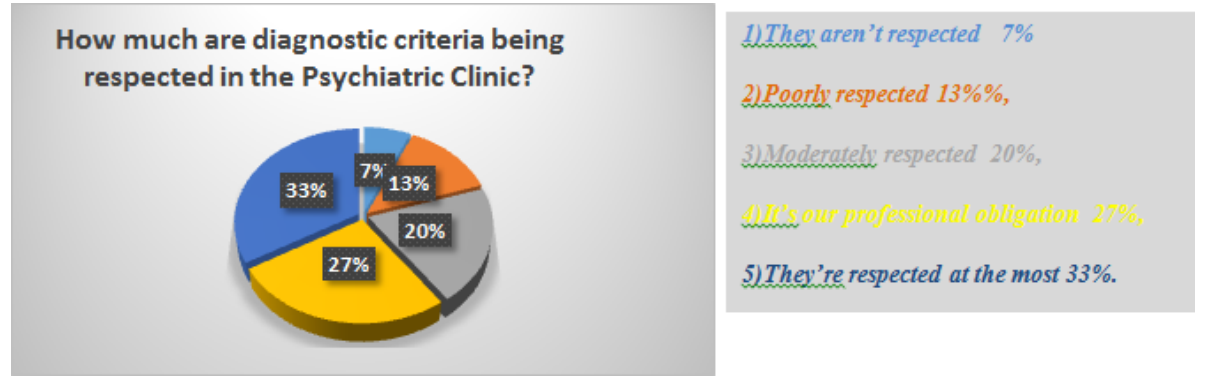

Chart 4.10. Diagnostic criteria are being respected but it's clear that there is still room for improvements.

\section{Discussions- Related to Survey's Results}

5.1. On the research question from the patients' questionnaire: How much are you informed by the medical staff about your illness?

The right to get informed about: the disease, their state, the illness prognosis, being able to get the most advanced treatment, the undesirable treatment effects, the risks and failures during the treatment- is the right which enables the patient to decide independently about his health and treatment.

The results have shown a low level of information. The clinic's practice still isn't ready and still doesn't have the professional desire to inform patients about their illness.

5.2. On the research question from the patients' questionnaire: Do you take your therapy voluntarily or are you being forced to do so?

The patients' right for "self-determination" related to medical treatment means that he/she has the right to decide freely if he/she wants to accept or refuse the treatment offered by the health services. This way, patients' choices and decisions are free and desirable.

The majority of patients have said that they are on the above the average level when it comes to the importance of therapeutic treatment related to their illness. This shows that the majority of patients are aware about their illness and the need for treatment.

5.3. On the research question from the patients' questionnaire: Have you ever been physically abused by the medical staff?

Professional mistakes and disrespecting the physical and psychic dignity in psychiatric institutions aren't rare, these mistakes tend to be hidden by the medical staff. The damaged patients and their families don't complain and this hinders the psychiatrist and nurse staff of being punished by ethical and legal authorities.

The results showed that there is an appreciable percentage of abuse but the majority denies that patients' abuse existed. Clinical practice didn't show results in complete reduction of physical abuse.

5.4. Medical staff's research question: How much are patients' rights, related to information about the illness, being respected in the Psychiatric Clinic?

The right to get informed about: the illness, their state, illness prognosis, the possibility of advanced treatment, undesirable treatment effects, the risks and failures during the treatment is an inalterable right protected by the international convention of Geneva. Based on this a concept has been developed about "information and self-determination" of the patient. The right information makes it possible for the patient to decide independently about his health and illness treatment.

The research results have shown that the level of respect for patients' rights about being informed about their illness by the medical staff is on a satisfactory level, but after comparing the results of the same question from patients' questionnaires we see that they are divergent.

5.5. Research question by the medical staff: Is the physical and psychic dignity of psychiatric patients being respected during their treatment in the Psychiatric Clinic?

The word "Dignity" has often been used in clinical lectures referring to and describing ideal conditions for treating patients, especially psychiatric patients who often were subjects of physical abuse in psychiatric clinics. Every violation of psychic and physical dignity not only influences the individual victim, but influences our society in general.

The research results showed that violation of psychiatric patients' rights by the medical staff is still present. Since their disclosure was anonymous this research allows us to understand that the psychiatric medical community is 
self-critical and conscious about the issue.

\subsection{Research question by the medical staff: Is the medical secret being respected by the medical staff in the psychiatric Clinic?}

Respecting the medical secret is one of the basic ethical values in psychiatry. Respecting confidentiality and information exchange within the health care team with the patient's consent shows respect and it is a part of the communication between the psychiatrics and patients. Respecting the patient's right for privacy and keeping the secret need to be great concerns while conducting psychiatric expertise. Psychiatrics' permanent obligation is to preserve confidentiality by always having in mind the legal context.

\section{Conclusions}

Bioethics and psychiatry, as two disciplines with different concepts, have used an approach of alternative thoughts in patients' interests and psychiatry has always been in concordance with ethical recommendations.

Psychiatry, like other medical branches faces many challenges because of new professions emersion and because of the society's request to get hold on their future in global industrialization. Public responsibilities are restricted by traditional paternal forms used in psychiatry. Global development brings rational forms which have to be harmonized with science by not skipping the rules posed by the society where we live.

Nowadays, numerous dilemmas occur in psychiatry. They appear as a consequence of the scientific and technologic progress. The progress in the care and treatment of patients with psychic disorders are crucial for improving the wellbeing of this stigmatized and often by the society forgotten population. The level on which persons with mental disorders ask for special protection from our society keeps being a controversial challenge.

The majority of people who suffer from mental illnesses, function relatively all right, therefore stigmatism from our society is unnecessary. Ethical principles have to be implemented with caution towards these patients' special weaknesses. Very often these patients with mental disorders refuse medical treatment. The psychiatric duty is to evaluate the competence which is defined by legal norms. Because of this, bioethics should be consulted as a second opinion, where the mental health laws came from, which allow the psychiatrist to treat patients against his will. The psychiatrist is entrusted with the evaluation of the psychic patient's state.

Population's awareness about the rights and obligations has led to the development of a new form of applied ethics, from which bioethics came as a new discipline of global ethics which is further closely related to the health care in psychiatry, to patients' autonomy in self-determination, to charity forms which aren't paternal and to seeking appropriate therapy.

The challenging psychiatric future and its support by bioethics are motives to think of and develop moral imagination.

\section{REFERENCES}

[1] Carmi, A., Schneider, S. \& Hefez, A., 1986.Psychiatry Law and Ethics. Berlin: Springer.

[2] Cowell, B., 1995.Developing a Basis for Moral Thinking. International Review of Education / Internationale Zeitschrift für Erziehungswissenschaft / Revue Internationale De L'education, 41(1/2), pp.33-45.

[3] Deutsch, E. \& Schreiber, H.-L., 1985.Medical Responsibility in Western Europe. 1e re. Berlin: Springer.

[4] Doyal, L. \& Sheather, J., 2005. Mental Health Legislation Should Respect Decision Making Capacity. BMJ: British Medical Journal, 331(7530), pp.1467-1469.

[5] Drane, J. F., 1994.Clinical Bioethics: Theory and Practice in Medical Ethical Decision-making. Lanham, USA: Rowman \& Littlefield.

[6] Edwards, R. B., 1997.Ethics of Psychiatry: Insanity, Rational Autonomy, and Mental Health Care. New York, USA: Prometheus Books.

[7] Fulford, K. M., 1990. Moral Theory and Medical Practice. Cambridge, UK: Cambridge University Press.

[8] George, R. E., Dogra, N. \& Fulford, B., 2015.Values and ethics in mental-health education and training: a different perspective. The Journal of Mental Health Training, Education and Practice, 10(3), pp.189-204.

[9] Gibson, J. L., Forman, L. \& Nixon, S. A., 2015.Bioethics and the Right to Health: Advancing a Complementary Agenda. Health and Human Rights, 17(1), pp.1-5.

[10] Helmchen, H. \& Sartorius, N., 2010.Ethics in Psychiatry European Contributions. Netherlands: Springer. 